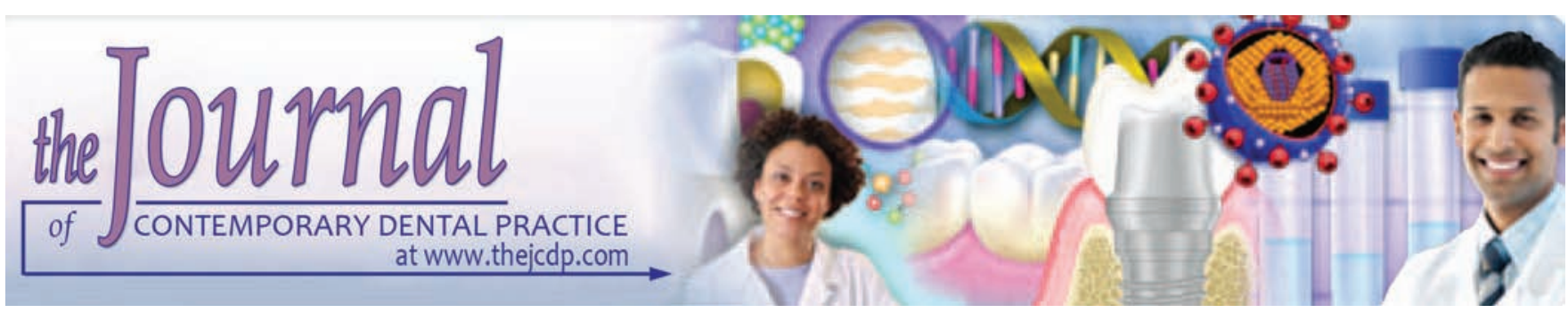

\title{
Choice of Endodontic Fiber Posts and its Influence on Dental Malpractice: An in vitro Evaluation
}

\author{
${ }^{1}$ Fouad Ayoub, ${ }^{2}$ Houssam Jassar, ${ }^{3}$ Hassan El Husseini, ${ }^{4}$ Ziad Salameh
}

\begin{abstract}
Aims and objectives: The fiber post type used in restoring endodontically treated teeth may affect the dental expert decision in the case of dental malpractice. The aim of this study was to evaluate the low-cost commercial fiber post in comparison with a higher cost or well-known documented fiber post system.
\end{abstract}

Materials and methods: A total of 20 premolars were selected for the study; following endodontic treatment, specimens were randomly divided into two groups of 10 specimens each according to the type of fiber post used: (1) Low-cost commercial fiber post (OYAPost, Taper Lucent, OYARICOM) and (2) higher cost well-known fiber post (Rely X Fiber post, 3M ESPE). Both fiber posts were cemented using self-adhesive cement (Rely $X$ Unicem). Samples were subjected to push-out bond strength and to failure analysis. One-way analysis of variance was used $(p<0.005)$.

Results: There was no significant difference between the bond strength of the two tested groups ( $p>0.05)$, while statistically significant difference $(p<0.05)$ was noted between the different post space regions (cervical, middle, and apical).

Conclusion: Based on the evidence from the study, it can be concluded that the type of fiber post should not affect the dental expert decision in the case of dental malpractice/lawsuit.

Clinical significance: All types of low-cost fiber posts may behave similarly to other higher cost or well-documented fiber posts.

\footnotetext{
${ }^{1}$ Department of Forensic Odontology and Human Identification Faculty of Dental Medicine Lebanese University, Beirut, Lebanon

${ }^{2}$ Department of Oral Surgery, Faculty of Dental Medicine Lebanese University, Beirut, Lebanon

${ }^{3}$ Department of Endodontics, Faculty of Dental Medicine Lebanese University, Beirut, Lebanon

${ }^{4}$ Department of Research and Prosthodontics, Faculty of Dental Medicine, Lebanese University, Beirut, Lebanon

Corresponding Author: Ziad Salameh, Department of Research and Prosthodontics, Faculty of Dental Medicine Lebanese University, Beirut, Lebanon, Phone: +0096171247147 e-mail: drzsalameh@gmail.com
}

Keywords: Dental malpractice, Endodontically treated teeth, Expert, Fiber post, Lawsuit.

How to cite this article: Ayoub F, Jassar H, El Husseini $H$, Salameh Z. Choice of Endodontic Fiber Posts and its Influence on Dental Malpractice: An in vitro Evaluation. J Contemp Dent Pract 2017;18(6):452-457.

\section{Source of support: Nil}

Conflict of interest: None

\section{INTRODUCTION}

Dental malpractice occurs when a dentist fails to follow the "standard of care," or generally accepted practice for treating a patient. For example, if a dentist caused nerve injuries, failed to diagnose oral cancer or periodontal disease, unnecessarily extracted teeth or extracted the wrong tooth, or deliver faulty restorations, patient may file a dental malpractice lawsuit and can appoint a qualified injury lawyer to help for compensation collection. ${ }^{1-3}$

With the increasing demands of esthetic restorations by patients, there was development by renowned or new companies to make novel materials to use in the same direction of esthetics and restorative dentistry. In case of a lawsuit involving a dental malpractice, with failure of an endodontically treated tooth restored with fiber post and composite core, the qualified attorney usually investigates the type/brand of post material used when restoring the failed tooth. ${ }^{4,5}$ The brand manufacturer of the fiber post may influence the attorney or dental expert decision in evaluating and putting down the final report.

Endodontically treated teeth usually present inadequate remaining coronal structure due to cavity preparation. ${ }^{6-8}$ The type of definitive restoration chosen to restore endodontically treated maxillary teeth may be influenced by the amount of hard tissues remaining after tooth preparation. ${ }^{9}$

Recently, the introduction of fiber-reinforced composite posts helped to improve stress distribution, as 
their elastic modulus is similar to that of dentin usually leading to fewer and more favorable fracture pattern as demonstrated by several in vivo $0^{10-12}$ and in vitro studies. ${ }^{13-16}$ Although posts are necessary to retain coronal build-up materials, they do not reinforce roots and may even weaken them through loss of radicular dentin necessitated by post space preparation, ${ }^{6,17}$ while several studies also suggested that glass fiber posts contributed to the reinforcement and strengthening of endodontically treated teeth under full coverage crowns.

The most common failure of restorations bonded with fiber posts is the dislodging of the posts from root canals. ${ }^{8,18-20}$ This is probably related to the highly unfavorable cavity configuration encountered within post spaces and the increased wall-to-wall contraction of resin films during polymerization. ${ }^{21,22}$ Therefore, to increase the success rate of the final restoration, several investigations have been directed toward improving retention of the post, including different pretreatment of the posts and dentin $^{23,24}$ or use of different luting cements. ${ }^{25,26}$

The aim of this study was to evaluate the mechanical properties in terms of bond strength and failure pattern of a low-cost commercial fiber post in comparison with higher cost well-known documented posts. The null hypothesis tested was that there is a difference between the two tested fiber posts.

\section{MATERIALS AND METHODS}

\section{Sample Preparation}

A total of 20 human single-rooted mandibular second premolars extracted due to orthodontic reasons were selected for this study. Teeth were subjected for radiographic and microscopic examination and were stored in a dark container in $0.5 \%$ chloramine- $\mathrm{T}$ at $4^{\circ} \mathrm{C}$ and used within 2 weeks after extraction. Teeth were decoronated $2 \mathrm{~mm}$ coronal to the most incisal point of the cementoenamel junction (CEJ) using a low-speed diamond saw (Isomet 2000, Buehler Ltd, Lake Bluff, NY, USA) under copious water cooling.

\section{Endodontic Treatment and Post Cementation}

A step-back technique was used for instrumentation with rotary nickel titanium (NiTi) instruments (Flex-Master, VDW, Munich, Germany). Canals were prepared to ISO size \#350.06 taper. The root canals were irrigated between instrumentation, and canal spaces were filled with irrigation solution during instrumentation phase. For each root canal, $2 \mathrm{~mL}$ of $5.25 \%$ solution of sodium hypochlorite (Clorox Co., Oakland, CA, USA) was delivered. Following final irrigation, canal spaces were completely dried with absorbent paper points (Dentsply Maillefer, Tulsa, OK, USA). Roots were obturated with thermoplasticized injectable gutta-percha (Obtura II, Model 823-600, Obtura Corp., 1663 Fenton Business Park, Fenton, MO, USA). After completion of endodontic treatment, teeth were stored in $100 \%$ humidity dark container for 7 days. Post spaces were prepared to a depth of $9 \mathrm{~mm}$ from CEJ, leaving a minimum apical seal of $4 \mathrm{~mm}$ of gutta-percha. Gutta-percha was removed using Gates Glidden drills. Specimens were randomly divided into two groups of 10 , each according to the type of fiber post (Table 1) used.

\section{Group I}

Post spaces were prepared using the drilling post of the "low-cost" commercial fiber post (OYAPost, Taper Lucent, OYARICOM, China) following the manufacturer's instructions. Posts were then luted using self-adhesive resin cement (Rely X Unicem, 3M ESPE, Seefeld, Germany).

\section{Group II}

Same procedure as group I but the posts used were different (Rely X Fiber post, 3M ESPE). Posts were then luted using self-adhesive resin cement (Rely X Unicem, 3M ESPE).

\section{Preparation of Specimens for the Push-out Bond Strength Test}

Each root portion with the cemented fiber post in each group was sectioned horizontally, into 1-mm-thick serial slices using the Isomet saw under water cooling (Isomet 2000, Buehler). Thickness of each slice was measured with a digital caliper. The push-out load was applied by testing device (Walter + Bai, AG, Switzerland). Cylindrical plunger was positioned so that it only contacts the bonded post upon loading. Each slice was positioned with its apical aspect facing the punch tip so that loading force introduced was in an apical-coronal direction. Loading was performed at a crosshead speed of $0.5 \mathrm{~mm} /$ minute until the post was dislodged from the root slice. Retentive strength of the post segment was expressed in $\mathrm{MPa}$, by dividing the load at failure (Newtons) by the interfacial area $\left(\mathrm{S}_{\mathrm{L}}\right)$ of the post

Table 1: Mean \pm SD of the push-out bond strengths of all the groups (in MPa)

\begin{tabular}{llllll}
\hline & & \multicolumn{2}{c}{ Prepared post space region (mean \pm SD) } & Significance \\
\cline { 3 - 5 } Groups & Overall mean \pm SD & Cervical & Middle & Apical & \\
\hline I & $12.33 \pm 1.04$ & $17.09 \pm 1.52$ & $12.83 \pm 0.93$ & $7.08 \pm 0.68$ & $0.007 \mathrm{~S}$ \\
II & $13.68 \pm 1.19$ & $18.83 \pm 1.74$ & $14.21 \pm 1.1$ & $8.02 \pm 0.73$ & $0.008 \mathrm{~S}$ \\
\hline
\end{tabular}

SD: Standard deviation; S: Significant 

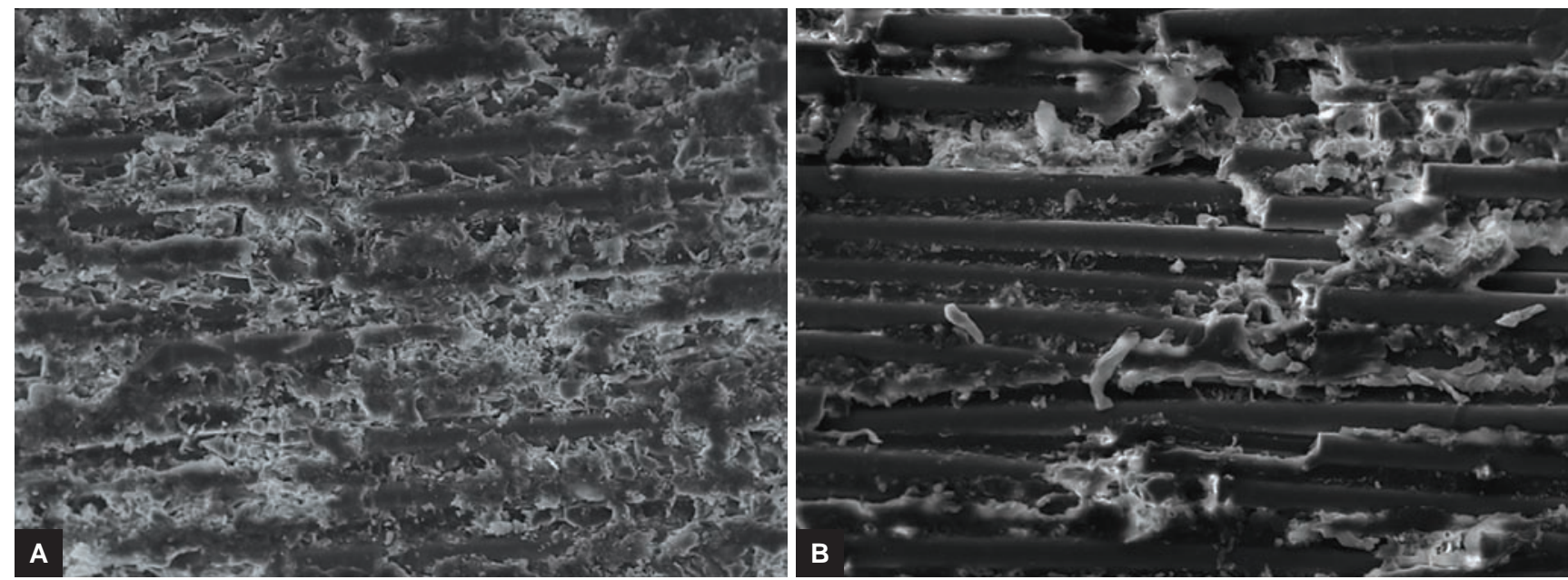

Figs 1 A and B: Scanning electron microscopy evaluation (500×) of (A) Rely X fiber post; and (B) OYAPost

fragment. The latter, being the lateral surface of a truncated cone, was calculated by the formula: $S_{L}=\pi(R+r)$ $\left[\mathrm{h}^{2}+(\mathrm{R}-\mathrm{r})^{2}\right]^{0.5}$, where $\pi=3.14, \mathrm{R}=$ Coronal post radius, $\mathrm{r}=$ Apical post radius, and $\mathrm{h}=$ Specimen slice thickness.

\section{Failure Type Analysis}

After push-out test, specimens were assessed initially under a stereomicroscope (Swift Stereo Eighty Microscope, Swift Instruments International SA, Tokyo, Japan) and then with scanning electron microscopy (SEM) (SERON AIS2100, Korea) to determine the type of failure classified as follows: Type I- adhesive, type II - cohesive, and type III - mixed failure.

\section{Scanning Electron Microscopy and Elemental Analysis}

Five posts from each post brand used in the study were subjected to SEM and elemental analysis (energy dispersive X-ray spectrometry [EDS]) (Fig. 1 and Graph 1).
The elemental analysis was performed to evaluate the composition of different tested posts and to assess the different elements in each post using a dispersive spectroscopy (EDAX Ametek) connected to the SEM machine.

\section{Statistical Analysis}

Statistical analyses were performed using Statistical Package for the Social Sciences version 15.0 software (SPSS Inc., Chicago, Illinois, USA). Push-out bond strength data were analyzed using one-way analysis of variance to compare the push-out bond strength results between the groups and different prepared post space regions (cervical, middle, and apical). Post hoc tests were performed; the level of significance was set at $\mathrm{p}<0.05$.

\section{RESULTS}

\section{Push-out Bond Strength}

Mean and standard deviation of push-out strength values of the two tested groups are shown in Table 2. There was
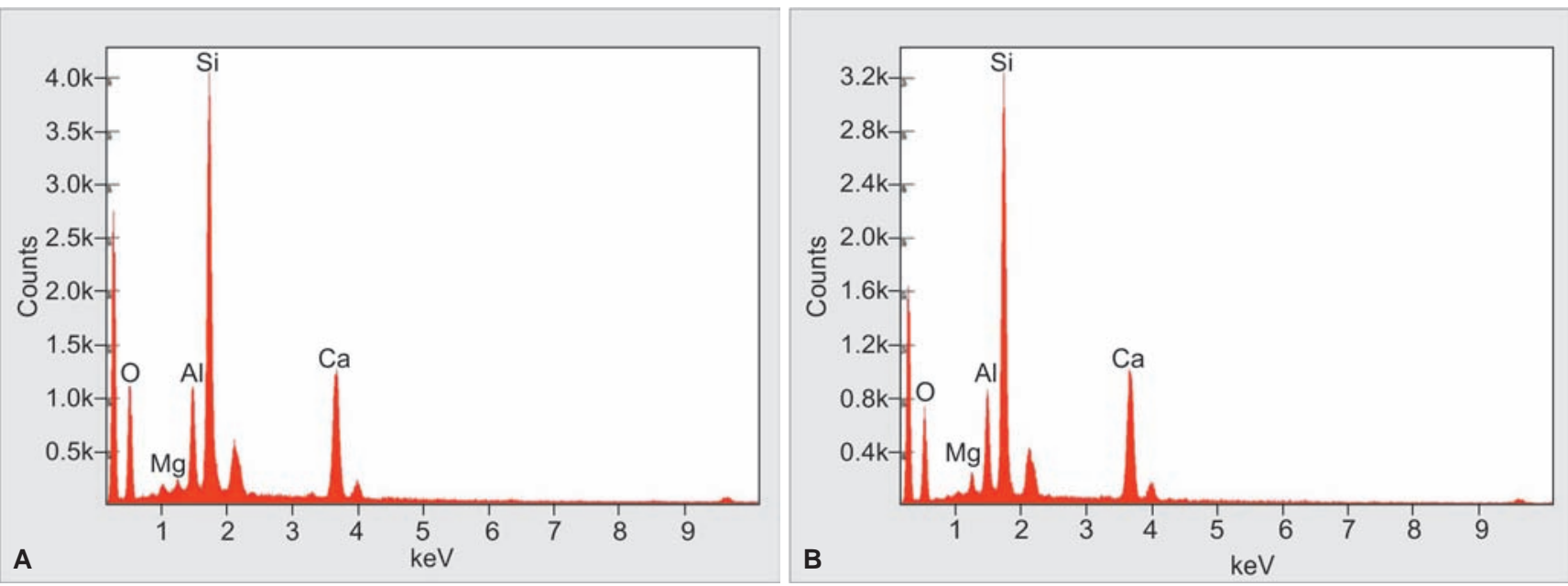

Graphs $1 A$ and B: Energy-dispersive X-ray spectrometry evaluation of (A) Rely X fiber post; and (B) OYAPost 
Table 2: Percentages of failure types among tested groups

\begin{tabular}{llll}
\hline Group & Adhesive (\%) & Cohesive (\%) & Mixed (\%) \\
\hline I & 67 & 25 & 8 \\
II & 72 & 23 & 5 \\
\hline
\end{tabular}

no significant difference between the bond strength of the two tested groups $(p>0.05)$, while significant difference $(p<0.05)$ was noted between the different post space regions (cervical, middle, and apical) (Table 2).

\section{Types of Failure}

With regard to failure type (Table 2), adhesive failure type I prevailed in both groups mainly between resin cement and the post followed by mixed adhesive failure type and then by cohesive failure. The SEM showed a resin matrix denser in Rely X Fiber post compared with the other post. In group II, EDS reported the presence of similar elements in both groups with higher concentration.

\section{DISCUSSION}

The results of this in vitro study led to the rejection of the null hypothesis that there is a difference between the two types of tested posts. The fiber post material property showed that it would affect its long-term success; the matrix composition and the embedded fibers (glass/ quartz) play an important role in stress distribution that impacts fatigue resistance over time. ${ }^{6}$ These posts have a modulus of elasticity comparable to that of dentin $(\sim 20$ GPa) that will dissipate most of the stresses to the final restoration, thereby avoiding concentration and by so unfavorable fracture. ${ }^{27}$

The Rely X fiber post showed a denser resin matrix when compared with the other group, which may explain the higher bond strength values obtained, while the difference was not significant. In addition, the use of selfadhesive resin cement has several advantages; it does not require any dentin pretreatment, it is less technique sensitive, and it is also time consuming for the operator and does not require moisture control as for the etch-rinse resin cement. $^{28}$

In contrast to regular resin cements, the main bonding mechanism of self-adhesive cements involves chemical chelation between functional acid methacrylates and calcium from tooth tissues. ${ }^{29}$ It could be hypothesized that chemical bonding produced by these materials results in a more stable bonding interface. A previous study demonstrated that self-adhesive resin cements support mechanical stress better than conventional resin cements. ${ }^{30}$ The high configuration factor (C-factor) of the root canal and the high polymerization shrinkage stress create unfavorable conditions for the intraroot bonding of fiber posts leading to lower dentin bond strengths. ${ }^{31,32}$
Bond strength values are also affected by the composition of the matrix of the post, ${ }^{33}$ as no chemical union exists between methacrylate-based resins and the epoxy resins of the post. ${ }^{34}$ Thus, the main factor contributing to the resistance to dislocation of bonded fiber post seems to be sliding friction..$^{35}$ Regarding pretreatment of the post with a coupling silane, one in vitro study revealed significant improvement in bond strength when a coupling silane was used. ${ }^{36}$ While another study showed no improvement after silanization, ${ }^{37}$ it must be noted that in this study the effect of silanization was not investigated and one type of glass fiber post was used. Our results of push-out bond strength for different prepared post space regions showed that bond strength was significantly affected by the region of prepared post space; higher values were obtained in the cervical section than for the middle and the apical sections, which are in agreement with other studies. ${ }^{38,39}$ This can be explained by the higher density and orientation of dentinal tubules in the cervical section. ${ }^{40}$

Analysis of failure mode showed that most failures occurred at post/cement interface, which is in agreement with other studies ${ }^{41}$ followed by mixed failures. These results showed that the post/cement interface was the weakest link in the system. The push-out bond strength reported can be a reproducible technique to measure bond strength inside root canal ${ }^{37}$ when compared with the microtensile bond strength. These results favor the hypotheses that "low-cost" commercial fiber posts used in restoring endodontically treated teeth should not be considered as the sole cause of failure of the restored tooth in case of lawsuit due to dental malpractice.

The brand manufacturer of the fiber post should not influence the attorney or dental expert decision in evaluating and putting down the final report as other factors should be evaluated including the dentist's skills, the luting cement, or the final restoration used.

\section{CONCLUSION}

Within the limitations of this study, the type of fiber posts used should not affect the dental expert decision-making in case of dental malpractice/lawsuit. The results of this study cannot be used to conclude that all types of lowcost fiber posts may behave similarly to other higher cost or well-documented fiber posts. Further investigations should be performed to validate the results of this study.

\section{REFERENCES}

1. Curley AW. Dental implant jurisprudence: avoiding the legal failures. J Indiana Dent Assoc 2002 Fall;81(3):29-34.

2. Giovanniello AF. Discourage malpractice lawsuits: a commonsense approach. J Calif Dent Assoc 1997 Mar;25(3):219-223.

3. Spindler J. Reduce your malpractice risk. Top 10 documenting mistakes to avoid. J Mich Dent Assoc 2015 Dec;97(12):24-29. 
4. Rosen E, Tsesis I, Tamse A, Bjørndal L, Taschieri S, Givol N. Medico-legal aspects of vertical root fractures in root filled teeth. Int Endod J 2012 Jan;45(1):7-11.

5. Givol N, Rosen E, Bjørndal L, Taschieri S, Ofec R, Tsesis I. Medico-legal aspects of altered sensation following endodontic treatment: a retrospective case series. Oral Surg Oral Med Oral Pathol Oral Radiol Endod 2011 Jul;112(1):126-131.

6. Akkayan B, Gülmez T. Resistance to fracture of endodontically treated teeth restored with different post systems. J Prosthet Dent 2002 Apr;87(4):431-437.

7. Sorrentino R, Aversa R, Ferro V, Auriemma T,ZaroneF, Ferrari M, Apicella A. Three-dimensional finite element analysis of strain and stress distributions in endodontically treated maxillary central incisors restored with different post, core and crown materials. Dent Mater 2007 Aug;23(8):983-993.

8. Skupien JA, Sarkis-Onofre R, Cenci MS, Moraes RR, PereiraCenci T. A systematic review of factors associated with the retention of glass fiber posts. Braz Oral Res 2015 Jun;29(1):pii.

9. Rippe MP, Santini MF, Bier CA, Baldissara P, Valandro LF. Effect of root canal preparation, type of endodontic post and mechanical cycling on root fracture strength. J Appl Oral Sci 2014 May-Jun;22(3):165-173.

10. Cagidiaco MC, Radovic I, Simonetti M, Tay F, Ferrari M. Clinical performance of fiber post restorations in endodontically treated teeth: 2-year results. Int J Prosthodont 2007 May-Jun;20(3):293-298.

11. Ferrari M, Vichi A, Mannocci F, Mason PN. Retrospective study of the clinical performance of fiber posts. Am J Dent 2000 May;13(Spec No):9B-13B.

12. Naumann M, Blankenstein F, Kiessling S, Dietrich T. Risk factors for failure of glass fiber-reinforced composite post restorations: a prospective observational clinical study. Eur J Oral Sci 2005 Dec;113(6):519-524.

13. Salameh Z, Sorrentino R, Papacchini F, Ounsi HF, Tashkandi E, Goracci C, Ferrari M. Fracture resistance and failure patterns of endodontically treated mandibular molars restored using resin composite with or without translucent glass fiber posts. J Endod 2006 Aug;32(8):752-755.

14. Salameh Z, Sorrentino R, Ounsi HF, Goracci C, Tashkandi E, Tay FR, Ferrari M. Effect of different all-ceramic crown system on fracture resistance and failure pattern of endodontically treated maxillary premolars restored with and without glass fiber posts. J Endod 2007 Jul;33(7):848-851.

15. Bitter K, Perdigão J, Exner M, Neumann K, Kielbassa A, Sterzenbach G. Reliability of fiber post bonding to root canal dentin after simulated clinical function in vitro. Oper Dent 2012 Jul-Aug;37(4):397-405.

16. Binus S, Koch A, Petschelt A, Berthold C. Restoration of endodontically treated teeth with major hard tissue loss bond strength of conventionally and adhesively luted fiberreinforced composite posts. Dent Traumatol 2013 Oct;29(5): 339-354.

17. Amarnath GS, Swetha MU, Muddugangadhar BC, Sonika R, Garg A, Rao TRP. Effect of post material and length on fracture resistance of endodontically treated premolars: an in-vitro study. J Int Oral Health 2015 Jul;7(7):22-28.

18. Wandscher VF, Bergoli CD, de Oliveira AF, Kaizer OB, Souto Borges AL, Limberguer IdaF, Valandro LF. Fatigue surviving, fracture resistance, shear stress and finite element analysis of glass fiber posts with different diameters. J Mech Behav Biomed Mater 2015 Mar;43:69-77.
19. Parisi C, Valandro LF, Ciocca L, Gatto MR, Baldissara P. Clinical outcomes and success rates of quartz fiber post restorations: a retrospective study. J Prosthet Dent 2015 Sep;114(3):367-372.

20. Penelas AG, Piedade VM, Borges AC, Poskus LT, da Silva EM, Guimarães JG. Can cement film thickness influence bond strength and fracture resistance of fiber reinforced composite posts? Clin Oral Investig 2016 May;20(4):849-855.

21. Tay FR, Loushine RJ, Lambrechts P, Weller RN, Pashley DH. Geometric factors affecting dentin bonding in root canals: a theoretical modeling approach. J Endod 2005 Aug;31(8):584-589.

22. Chen Q, Wei XY, Yi M, Bai YY, Cai Q, Wang XZ. Effect on the bond strengths of glass fiber posts functionalized with polydopamine after etching with hydrogen peroxide. Dent Mater J 2015 Mar;34(6):740-745.

23. GoracciC,FabianelliA, SadekFT, PapacchiniF, Tay FR, FerrariM. The contribution of friction to the dislocation resistance of bonded fiber posts. J Endod 2005 Aug;31(8):608-612.

24. Altmann AS, Leitune VC, Collares FM. Influence of eugenolbased sealers on push-out bond strength of fiber post luted with resin cement: systematic review and meta-analysis. J Endod 2015 Sep;41(9):1418-1423.

25. Farina AP,Chiela H,Carlini-Junior B, Mesquita MF,MiyagakiDC, Randi Ferraz CC, Vidal CM, Cecchin D. Influence of cement type and relining procedure on push-out bond strength of fiber posts after cyclic loading. J Prosthodont 2016 Jan;25(1):54-60.

26. Kurthukoti AJ, Paul J, Gandhi K, Rao DB. Fracture resistance of endodontically treated permanent anterior teeth restored with three different esthetic post systems: an in vitro study. J Indian Soc Pedod Prev Dent 2015 Sep;33(4):296-301.

27. Goracci C, Grandini S, Bossù M, Bertelli E, Ferrari M. Laboratory assessment of the retentive potential of adhesive posts: a review. J Dent 2007 Nov;35(11):827-835.

28. Reis KR, Spyrides GM, Oliveira JA, Jnoub AA, Dias KR, Bonfantes G. Effect of cement type and water storage time on the push-out bond strength of a glass fiber post. Braz Dent J 2011;22(5):359-364.

29. Durski MT, Metz MJ, Thompson JY, Mascarenhas AK, Crim GA, Vieira S, Mazur RF. Push-out bond strength evaluation of glass fiber posts with different resin cements and application techniques. Oper Dent 2016 Jan-Feb;41(1):103-110.

30. Moraes RR, Boscato N, Jardim PS, Schneider LF. Dual and self-curing potential of self-adhesive resin cements as thin films. Oper Dent 2011 Nov-Dec;36(6):635-642.

31. Bouillaguet S, Troesch S, Wataha JC, Krejci I, Meyer JM, Pashley DH. Microtensile bond strength between adhesive cements and root canal dentin. Dent Mater 2003 May;19(3): 199-205.

32. Zicari F, Couthino E, De Munck J, Poitevin A, Scotti R, Naert I, Van Meerbeek B. Bonding effectiveness and sealing ability of fiber-post bonding. Dent Mater 2008 Jul;24(7):967-977.

33. Mannocci F, Sherriff M, Watson TF, Vallittu PK. Penetration of bonding resins into fibre-reinforced composite posts: a confocal microscopic study. Int Endod J 2005 Jan;38(1):46-51.

34. Monticelli F, Toledano M, Tay FR, SadekFT, GoracciC, Ferrari M. A simple etching technique for improving the retention of fiber posts to resin composites. J Endod 2006 Jan;32(1):44-47.

35. Aksornmuang J, Nakajima M, Foxton RM, Tagami J. Regional bond strengths of a dual-cure resin core material to translucent quartz fiber post. Am J Dent 2006 Feb;19(1):51-55.

36. Sorensen JA, Martinoff JT. Clinically significant factors in dowel design. J Prosthet Dent 1984 Jul;52(1):28-35. 
37. Goracci C, Tavares AU, Fabianelli A, Monticelli F, Raffaelli O, Cardoso PC, Tay F, Ferrari M. The adhesion between fiber posts and root canal walls: comparison between microtensile and push-out bond strength measurements. Eur J Oral Sci 2004 Aug;112(4):353-361.

38. Mallmann A, Jacques LB, Valandro LF, Mathias P, Muench A. Microtensile bond strength of light- and self-cured adhesive systems to intraradicular dentin using a translucent fiber post. Oper Dent 2005 Jul-Aug;30(4):500-506.
39. Ferrari M, Mannocci F, Vichi A, Cagidiaco MC, Mjör IA. Bonding to root canal: structural characteristics of the substrate. Am J Dent 2000 Oct;13(5):255-260.

40. Drummond JL. In vitro evaluation of endodontic posts. Am J Dent 2000 Jun;13(Spec No):5B-8B.

41. Sadek FT, Monticelli F, Goracci C, Tay FR, Cardoso PE, Ferrari M. Bond strength performance of different resin composites used as core materials around fiber posts. Dent Mater 2007 Jan;23(1):95-99. 